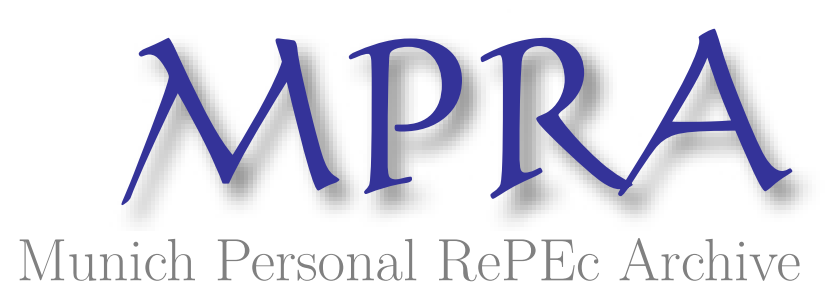

\title{
On the Equivalence of Tariffs and Quotas with Incomplete Information
}

Ning, Haokai

Department of Economics, York University

1 February 2020

Online at https://mpra.ub.uni-muenchen.de/101512/

MPRA Paper No. 101512, posted 05 Jul 2020 16:26 UTC 


\title{
On the Equivalence of Tariffs and Quotas with Incomplete Information*
}

\author{
Haokai Ning ${ }^{\dagger}$
}

\begin{abstract}
This paper compares the social welfare effects of tariffs and quotas as strategic trade policy instruments in an oligopolistic industry where the domestic market demand is uncertain and the policy is chosen before the uncertainty is resolved. The uncertain demand, once realized, is assumed to be available only to the domestic firm when the output game is played between domestic and foreign firms. To highlight our assertion, a simple scenario with linear demand, additive stochastic market shock, homogeneous products, and identical constant marginal costs is considered. It is shown that a tariff is superior to a quota regardless of the degree of uncertainty. Moreover, we also show that a prohibitive quota that results in autarky is always preferred to a quota at the free-trade level.
\end{abstract}

Journal of Economic Literature Classification Number: C72, D82, F13, L13.

Keywords: Incomplete Information, Uncertainty, Bayesian Nash equilibrium, Tariff, Quota.

\footnotetext{
*I thank Professors Mahmudul Anam, Shin-Hwan Chiang, and Kin Chung Lo for their encouragement and valuable comments. All remaining errors are my own responsibility.

$\dagger^{\dagger}$ Department of Economics, York University. E-mail: neoning@yorku.ca
} 


\section{Introduction}

The equivalence/non-equivalence of tariffs and quotas has attracted considerable attention ever since the seminal work by Bhagwati $(1965,1968)$. Bhagwati (1965) sets up a two-sector general equilibrium model to demonstrate that the equivalence of tariffs and quotas holds if domestic market is perfectly competitive but not if it is monopolized. Subsequently, Shibata (1968) shows that the equivalence can still hold as long as the domestic market is perfectly competitive but imports come from a foreign monopolist.

Although Bhagwati $(1965,1968)$ and Shibata $(1968)$ recognize the importance of market structure in studying the equivalence between tariffs and quotas, the effect of market structure on the issue of equivalence had not been rigorously analyzed until 1980s, notably by Itoh and Ono (1984). They construct a Bertrand duopoly model with heterogeneous products and show that the domestic price is lower under a tariff than under an equivalent quota. Using a conjectural variation approach under duopolistic quantity competition, Hwang and Mai (1988) show that the equivalence holds only under Cournot equilibrium. The domestic price is higher (lower) under a tariff than the equivalent quota if the market becomes less (more) competitive than Cournot. Similarly, Fung (1989) compares the effects of tariffs and quotas under Cournot-Nash and Stackelberg, and argues that tariffs and quotas can only be equivalent if firms are Cournot-Nash producers with heterogeneous goods. The domestic prices are lower under a tariff than a quota if the domestic firm is a Stackelberg leader, but the two prices are equal if the domestic firm behaves like a Cournot-Nash producer. While most studies primarily focus on the price equivalence of tariffs and quotas, little attention has been given to the equivalence in terms of social welfare. In our opinion, the social welfare equivalence is more important than the price equivalence since the governments consider not only producers but also consumers as a whole in prescribing their policies.

It is clear that the market structure plays an important role in determining the equivalence of tariffs and quotas. Other than the market structure, demand uncertainty can be another important factor that leads to the result of non-equivalence between tariffs and quotas. Weitzman (1974) considers the choice between price and quantity regimes under uncertainty. He shows that the flexibility provided by a price control regime is more desirable with sufficiently high market volatility, but such a flexibility ceases to exist when price control is replaced by quantity control. Fishelson and Flatters (1975) compare tariffs and quotas for a country facing a less than perfectly elastic foreign supply curve. They point out that, even in a perfectly competitive market, the equivalence of tariffs and quotas 
breaks down when the domestic and the foreign supply and demand are stochastic. They argue that the stochastic behavior of market uncertainty can arise from the random disturbances of supply and demand. Dasgupta and Stiglitz (1977) show a tariff is unambiguously superior to a quota in a general equilibrium model with uncertain demand.

Along the same line, Cooper and Riezman (1989) construct a third-country model based on this insight and show that the choice between export subsidies and export quotas depend on the degree of market uncertainty. Specifically, they demonstrate that export subsidies are potentially more desirable from the point of view of the exporting country with high uncertainty when firms have more information than governments. By contrast, Chen and Hwang (2006) examine a similar issue in the context of an importing country and demonstrate that when firms have more information than the government, flexibility becomes less desirable as degree of market uncertainty rises. In short, a tariff would be preferred to a quota by the importing country when market volatility is sufficiently low and the reverse is true otherwise.

Clearly, both market structure and uncertainty are known to be the two major factors affecting the equivalence between tariffs and quotas. ${ }^{1}$ No attention, however, has been given to the role of incomplete or asymmetric information ${ }^{2}$ on the issue of equivalence. To highlight this, we assume that the domestic firm has more information about the demand conditions than its foreign rival. The information disadvantage facing the foreign firm could arise because of consumers' preferences that are less transparent or idiosyncratic shocks that are far less predictable to the foreign-based company. The purpose of this paper is to reexamine the issue of tariff-quota equivalence under incomplete information in a stochastic duopoly model and then compare the social welfare rankings with one fully-informed domestic firm competing with one uninformed foreign firm in the domestic market à la Cournot.

Unlike the findings in Chen and Hwang (2006), we show that the domestic country turns out to have the same amount of option values under tariffs and quotas. Moreover, we show that a tariff is always superior to a quota regardless of market uncertainty. Under incomplete information, a quota at the free trade level can never emerge as an equilibrium outcome. By decomposing the expected

\footnotetext{
${ }^{1}$ Ning (2020a) extends Cooper and Riezman (1989) by incorporating incomplete information at industrial level. He shows that flexibility is no longer desirable when one firm has more information about the third market than the other firm, and thus export quota becomes a strictly dominant strategy for the country with less informed firm. Moreover, Ning (2020b) integrates incomplete information at industrial level to a reciprocal dumping model. On the other hand, Matschke (2003) constructs a screening model with Cournot competition and shows that asymmetric information can influence the equivalence of tariffs and quotas. However, she assumes that domestic government captures the entire quota rent to ensure an interior solution for an optimal quota level. This assumption is quite arbitrary as admitted by the author, and will not be made in this paper.

${ }^{2}$ In this paper, we interchangeably use terms incomplete information and asymmetric information as information partition in our model.
} 
social welfare under different policy instruments, we find that flexibility offered by tariffs increases consumer's surplus and tax revenue that more than offsets decrease in producer's surplus when the domestic government moves from a quota to a tariff policy.

The paper is organized as follows. Section 2 outlines our theoretical framework. Section 3 derives the expected level of social welfare for both tariff and quota regimes using a game theoretical approach. Section 4 ranks the expected social welfare under different policy instruments. Finally, section 5 presents the concluding remarks.

\section{The Model}

Following Hwang and Mai (1988), we assume that there are two firms, one domestic firm (denoted as firm 1) and one foreign firm (denoted as firm 2), both of which produce a homogeneous product for the domestic market. ${ }^{3}$ These firms are identical except for their country of operation if there is no government intervention. Assume each firm produces final goods at a constant marginal cost of $c>0$. Profits from the production of $q_{i}$ units of output for firm $i$ is therefore $\pi_{i}: q_{i} \rightarrow \mathbb{R}^{+} \cup\{0\}$ :

$$
\pi_{i}=(p-c) q_{i}
$$

for $i=1,2$, and $p$ is the market price of the final goods firm $i$ is selling.

All consumers in question reside in country 1 (i.e., the domestic country). For simplicity, we assume that the domestic government is the sole decision maker in choosing the instruments and levels of trade intervention against the foreign firm, whereas the foreign government is passive. The demand in the domestic country is uncertain, assumed to take the following linear form:

$$
p=a-b Q+\varepsilon
$$

where $Q=q_{1}+q_{2}$ is the total output produced by the domestic firm $\left(q_{1}\right)$ and the foreign firm $\left(q_{2}\right)$. The parameters $a(>c)$ and $b$ are both positive and $\varepsilon$ is a random variable which reflects domestic market uncertainty. For illustration purpose, we assume $\varepsilon$ could take only two possible values:

$$
\varepsilon \in \Omega \equiv\{-V, V\},
$$

\footnotetext{
${ }^{3}$ Our results are readily to be extended with $N_{1}$ numbers of domestic firms and $N_{2}$ numbers of foreign firms.
} 
where $V \in \mathbb{R}$ and the subjective common prior probability measure over $\Omega$ is assumed to be $(\theta, 1-\theta)$. That is, we assume the bad state $-V$ and the good state $V$ occur with probability $\theta$ and $1-\theta$, respectively.

The game consists of two stages. In the first stage, the domestic government chooses the optimal policy mode and level in terms of tariff or quota to maximize its expected social welfare level before the realization of $\varepsilon$. At the beginning of stage two, the random variable $\varepsilon$ is realized, but the information is only available to the domestic firm. Both firms then select their output to maximize profits given the optimal policy level imposed by the domestic government. Figure 1 shows the timing and the partial resolution of uncertainty. In this setting, only the domestic firm has the complete information about the true state of the world, neither the domestic government nor the foreign firm possess this piece of information.

Figure 1: Timing of Two-Stage Trade Game with Incomplete Information

\begin{tabular}{|c|c|c|c|c|}
\hline Stage 1 & & Beginning of Stage 2 & & Stage 2 \\
\hline $\begin{array}{c}\text { Domestic government } \\
\text { selects policy } \\
\text { mode and level }\end{array}$ & $\rightarrow$ & $\begin{array}{c}\text { Trade policy is chosen } \\
\text { and } \\
\text { domestic firm observes } \varepsilon\end{array}$ & $\rightarrow$ & $\begin{array}{l}\text { Firms play } \\
\text { the output } \\
\text { game }\end{array}$ \\
\hline
\end{tabular}

Without loss of generality, we assume $\theta=\frac{1}{2}$ in the subsequent analysis. Given this, the expected value of the random variable is $E(\varepsilon)=0$, and the corresponding variance is $\operatorname{Var}(\varepsilon)=V^{2}=\sigma^{2}$. In what follows, a backward induction approach is used to solve the two-stage trade game with incomplete information. Since stage two Cournot game is a strategic game with incomplete information, we shall adopt Bayesian Nash equilibrium concept in solving equilibrium outputs for both firms. By using this solution concept, we can guarantee the equilibrium is a perfect Bayesian equilibrium.

\section{Subgame Equilibrium}

In this section, we derive equilibrium output levels for both firms in stage two using Bayesian Nash equilibrium concept under tariffs and quotas, respectively. The expected social welfare level of the domestic government is then calculated by reverting back to stage one given that the domestic government anticipates Bayesian Nash equilibrium output levels in the subsequent stage.

Given that the domestic firm has full information about the domestic market demand in stage two, we shall not exclude the possibility that the domestic firm may choose to opt out of the market 
when the realized $\varepsilon$ is too low. However, for presentation purpose, we assume that random variable $V$ falls in a range such that the domestic firm's output is positive under tariffs even when realized domestic market demand is low. The welfare ranking under different policy instruments still holds if we relax this assumption. A more detailed analysis of welfare ranking under tariffs and quotas when this assumption of stochastic term $V$ is relaxed can be found in Appendix.

\subsection{Import Tariffs}

Without loss of generality, assume that the demand is sufficiently high so that both firms remain active under tariffs even if the realized $\varepsilon$ is $-V$. As shown below, this happens when $V<\frac{8}{9}(a-c)$. $^{4}$

Suppose the domestic government imposes a tariff on imported goods at a rate of $t$. Since the domestic firm is able to observe the true state of domestic market demand at the beginning of stage two, the problems for the domestic firm are

$$
\begin{aligned}
\max _{q_{1 L}^{T}} \pi_{1 L}^{T} & =\left(a-b\left(q_{1 L}^{T}+q_{2}^{T}\right)-V\right) q_{1 L}^{T}-c q_{1 L}^{T}, \\
\max _{q_{1 H}^{T}} \pi_{1 H}^{T} & =\left(a-b\left(q_{1 H}^{T}+q_{2}^{T}\right)+V\right) q_{1 H}^{T}-c q_{1 H}^{T},
\end{aligned}
$$

where $q_{1 L}^{T}, q_{1 H}^{T}, \pi_{1 L}^{T}$ and $\pi_{1 H}^{T}$ are output decision and profits of the domestic firm under tariff policy regime (denoted by superscripts $T$ ) if the true domestic market demand is low or high, respectively. The foreign firm cannot observe the true market demand in the domestic country, hence its objective function under tariff regime given the common prior is

$$
\max _{q_{2}^{T}} E\left(\pi_{2}^{T}\right)=\frac{1}{2} \sum_{\varepsilon \in \Omega}\left(a-b\left(q_{1}^{T}+q_{2}^{T}\right)+\varepsilon\right)-c q_{2}^{T}-t q_{2}^{T}
$$

where $q_{1}^{T} \in\left\{q_{1 L}^{T}, q_{1 H}^{T}\right\}^{5}$ depend on the realization of $\varepsilon$. The best response functions for the above maximization problems are

$$
\begin{aligned}
B R_{1 L}\left(q_{2}^{T}\right) & =q_{1 L}^{T} \in \arg \max \pi_{1 L}^{T}, \\
B R_{1 H}\left(q_{2}^{T}\right) & =q_{1 H}^{T} \in \arg \max \pi_{1 H}^{T}, \\
B R_{2}\left(q_{1 L}^{T}, q_{1 H}^{T}\right) & =q_{2}^{T} \in \arg \max E\left(\pi_{2}^{T}\right) .
\end{aligned}
$$

\footnotetext{
${ }^{4}$ The equilibrium analysis under tariff policy for $V \geq \frac{8}{9}(a-c)$ can be found in Appendix A.

${ }^{5}$ Henceforth, we use subscript $L$ and $H$ to denote the output level and profits for the domestic firm in low and high domestic market demand, respectively.
} 
Given these best response functions, we can obtain the Bayesian Nash equilibrium points for any given tariff $t$ as follows:

$$
\begin{aligned}
q_{1 L}^{T} & =\frac{1}{3 b}(a-c+t)-\frac{V}{2 b} \\
q_{1 H}^{T} & =\frac{1}{3 b}(a-c+t)+\frac{V}{2 b} \\
q_{2}^{T} & =\frac{1}{3 b}(a-c-2 t) .
\end{aligned}
$$

The solutions characterize the Bayesian Nash equilibrium in the domestic market given $(t, V)$. Note that in order to make the domestic firm active when the market demand is low, we must have $V<\frac{2}{3}(a-c+t)$ for any given level of tariff set by the domestic government in the previous stage. ${ }^{6}$ Also notice that a higher value of $t$ increases output of the domestic firm, and a higher value of $t$ decreases output of the foreign firm. Furthermore, It is worth noting that the bigger the value of $V$, the higher (lower) the output of domestic firm in high (low) demand states.

Going back to the first stage, the domestic government maximizes the expected social welfare with respect to tariff, given that the domestic government can fully anticipate output of both firms at Bayesian Nash equilibrium level. The social welfare function of the domestic country under tariff regime is specified as the sum of producer's surplus (profits of the domestic firm), consumer's surplus, and tariff revenue. The domestic government therefore sets the tariff rate so as to maximize the expected social welfare function:

$$
\begin{aligned}
\max _{t} E\left(S W^{T}\right) & =\frac{1}{2}\left(P S_{L}^{T}+C S_{L}^{T}\right)+\frac{1}{2}\left(P S_{H}^{T}+C S_{H}^{T}\right)+T R \\
& =\frac{1}{2}\left(\pi_{1 L}^{T}+\frac{b}{2}\left(q_{1 L}^{T}+q_{2}^{T}\right)^{2}\right)+\frac{1}{2}\left(\pi_{1 H}^{T}+\frac{b}{2}\left(q_{1 H}^{T}+q_{2}^{T}\right)^{2}\right)+t q_{2}^{T},
\end{aligned}
$$

where

$$
\begin{aligned}
\pi_{1 L}^{T} & =\frac{1}{36 b}(2(a-c+t)-3 V)^{2} \\
\pi_{1 H}^{T} & =\frac{1}{36 b}(2(a-c+t)+3 V)^{2}
\end{aligned}
$$

Solving yields

$$
t^{*}=\frac{1}{3}(a-c) .
$$

\footnotetext{
${ }^{6}$ It is straightforward to show that the domestic firm will always produce in high domestic market demand by our assumption of $V$ and relevant parameters.
} 
Note that the introduction of uncertainty has no effect on the optimal tariff level. This is not surprising since the domestic government does not know the true state when making the decision by assumption, and the subjective common prior over $\Omega$ makes the expected value of random variable zero. ${ }^{7}$ Substituting (5) into best response function of the domestic firm in low demand market, we can update the critical point of $V$ such that the domestic firm shuts down in low demand state. This gives us $V<\frac{8}{9}(a-c)$ or $\sigma^{2}<\frac{64}{81}(a-c)^{2}$ in terms of variance.

Substituting the optimal tariff into Bayesian Nash equilibrium output levels yields the equilibrium levels of output for both firms under the tariff regime:

$$
\begin{aligned}
q_{1 L}^{T} & =\frac{4}{9 b}(a-c)-\frac{V}{2 b}, \\
q_{1 H}^{T} & =\frac{4}{9 b}(a-c)+\frac{V}{2 b}, \\
q_{2}^{T} & =\frac{1}{9 b}(a-c) .
\end{aligned}
$$

For comparison, we now examine the case where both firms are able to observe $\varepsilon$. In this case, the second stage Cournot game becomes strategic game with complete information when there is full information at the industrial level. Both firms now have flexibility by adjusting their output levels based on true market demand under tariff regime. Given this, one can easily verify that the optimal tariff rate is identical to the one given in equation (5) and the corresponding optimal output levels (denoted as ' for complete information case) for each firm are

$$
\begin{aligned}
q_{1 L}^{\prime} & =\frac{4}{9 b}(a-c)-\frac{V}{3 b}, \\
q_{1 H}^{\prime} & =\frac{4}{9 b}(a-c)+\frac{V}{3 b}, \\
q_{2 L}^{\prime} & =\frac{1}{9 b}(a-c)-\frac{V}{3 b}, \\
q_{2 H}^{\prime} & =\frac{1}{9 b}(a-c)+\frac{V}{3 b} .
\end{aligned}
$$

A comparison with the outputs under incomplete information is now in order. Clearly, the domestic firm tends to be more conservative (aggressive) when the demand is low (high) under incomplete information than under full information. This can be understood as follows. The uninformed foreign firm produces an output that maximizes its expected profits. Such an output is state independent,

\footnotetext{
${ }^{7}$ In a more general subjective common prior setting, i.e., a probability measure $(\theta, 1-\theta)$ over uncertainty space, the optimal tariff rate is $t^{*}=\frac{1}{3}(a-c+E(\varepsilon))$. We can see that the magnitude of optimal tariff is affected by the (subjective) expected value of random variable.
} 
which is seen in equation (8) as a weighted average of $q_{2 L}^{\prime}$ and $q_{2 H}^{\prime}$. In response to this, the domestic firm is able to take advantage of full information about market conditions by producing relatively less (more) with an intention to capture the "monopoly" rents in bad (good) market. The relative aggressiveness by the domestic firm can therefore be viewed as a strategic response to information disadvantage facing the foreign firm,

It can be easily verified that the expected social welfare for the domestic country under tariff regime with complete information is

$$
E\left(S W^{\prime}\right)=\frac{7}{18 b}(a-c)^{2}+\frac{1}{3 b} \sigma^{2}
$$

whereas the corresponding expected social welfare for the domestic country under tariff regime with incomplete information is

$$
E\left(S W^{T}\right)=\frac{7}{18 b}(a-c)^{2}+\frac{3}{8 b} \sigma^{2}
$$

It is straightforward to show that $E\left(S W^{T}\right)-E\left(S W^{\prime}\right)>0$ given any level of $\sigma^{2}$. To summarize, we have the following proposition:

Proposition 1. Under tariffs with incomplete information, the informed domestic firm produces less (more) relative to the full information case when the realized demand is low (high), whereas the uninformed foreign firm produces a moderate level of output. Moreover, the domestic firm's information advantage against the foreign firm results in higher expected social welfare for the domestic country.

It is worth noting that the second term in the expected social welfare expression of the domestic country $E\left(S W^{T}\right)$ is the option value associated with information advantage. The intuition behind this is simple. Being well-informed, the domestic firm is able to fully capture the benefit that results from the flexibility it enjoys. This consequently enhances firm's profits and hence the social welfare. The idea is similar to the option value in financial economics where the option value is positively related to market volatility. To see this, calculate $\frac{\partial E\left(S W^{T}\right)}{\partial \sigma^{2}}=\frac{3}{8 b}>0$, yielding

Proposition 2. Under tariff regime, higher degree of uncertainty implies higher expected social welfare for the domestic country due to the option value effects.

Next, we examine the expected social welfare for the domestic country under quotas. 


\subsection{Import Quotas}

Instead of imposing a tariff on the imported goods, the domestic government can alternatively choose to limit the quantity of imports through quotas. Our task is to evaluate the effect of such quantity restrictions on firm's behavior and the social welfare.

With no information about true domestic demand, the foreign firm is assumed to produce an output that is set by the domestic government. That is, the quota facing the foreign firm is assumed to be binding. Given this, the domestic firm would, therefore, choose the level of output to maximize its profit after the demand becomes known in stage two. Let $\bar{q}_{2}^{Q}$ be the maximum quantity that the foreign firm is permitted to sell in the domestic market, where the superscript $Q$ is used to represent the variable choice under quota. The objective functions for the domestic firm in different states of nature are:

$$
\begin{aligned}
& \max _{q_{1 L}^{Q}} \pi_{1 L}^{Q}=\left(a-b\left(q_{1 L}^{Q}+\bar{q}_{2}^{Q}\right)-V\right) q_{1 L}^{Q}-c q_{1 L}^{Q}, \\
& \max _{q_{1 H}^{Q}} \pi_{1 H}^{Q}=\left(a-b\left(q_{1 H}^{Q}+\bar{q}_{2}^{Q}\right)+V\right) q_{1 H}^{Q}-c q_{1 H}^{Q} .
\end{aligned}
$$

Solving these optimization problems yields optimal outputs across states under quotas:

$$
\begin{aligned}
q_{1 L}^{Q} & =\frac{1}{2 b}(a-c-V)-\frac{1}{2} \bar{q}_{2}^{Q} \\
q_{1 H}^{Q} & =\frac{1}{2 b}(a-c+V)-\frac{1}{2} \bar{q}_{2}^{Q} .
\end{aligned}
$$

The social welfare under the quota regime is defined as the sum of producer's surplus and consumer's surplus. Specifically, we can write the problem for the domestic government as

$$
\begin{aligned}
\max _{\bar{q}_{2}^{Q}} E\left(S W^{Q}\right) & =\frac{1}{2}\left(P S_{L}^{Q}+C S_{L}^{Q}\right)+\frac{1}{2}\left(P S_{H}^{Q}+C S_{H}^{Q}\right) \\
& =\frac{1}{2}\left(\pi_{1 L}^{Q}+\frac{b}{2}\left(q_{1 L}^{Q}+\bar{q}_{2}^{Q}\right)^{2}\right)+\frac{1}{2}\left(\pi_{1 H}^{Q}+\frac{b}{2}\left(q_{1 H}^{Q}+\bar{q}_{2}^{Q}\right)^{2}\right),
\end{aligned}
$$


where

$$
\begin{aligned}
\pi_{1 L}^{Q} & =\frac{1}{4 b}\left(a-c-V-b \bar{q}_{2}^{Q}\right)^{2} \\
\pi_{1 H}^{Q} & =\frac{1}{4 b}\left(a-c+V-b \bar{q}_{2}^{Q}\right)^{2} .
\end{aligned}
$$

The associated first- and second-order conditions for welfare maximization with respect to quotas are

$$
\begin{aligned}
\frac{\partial E\left(S W^{Q}\right)}{\partial \bar{q}_{2}^{Q}} & =\frac{3}{4} b \bar{q}_{2}^{Q}-\frac{1}{4}(a-c)=0, \\
\frac{\partial^{2} E\left(S W^{Q}\right)}{\partial\left(\bar{q}_{2}^{Q}\right)^{2}} & =\frac{3}{4} b>0 .
\end{aligned}
$$

Clearly, the second-order condition for social welfare maximization is violated. Hence, an interior solution does not exist. ${ }^{8}$ Given this, the optimal quota level will be either zero or at the free-trade level. To determine which one is better for the domestic country, it requires us to compare the social welfare levels between these two choices.

\section{Zero Quota}

In this case, $\bar{q}_{2}^{Q}=0$. Given our assumption that $V<\frac{8}{9}(a-c)$, the domestic firm will always be active under zero quota regardless of what the realized demand is. By substitution, $q_{1 L}^{Q}$ and $q_{1 H}^{Q}$ are reduced to (relabelling them by superscript $Z Q$ )

$$
\begin{aligned}
& q_{1 L}^{Z Q}=\frac{1}{2 b}(a-c-V) \\
& q_{1 H}^{Z Q}=\frac{1}{2 b}(a-c+V)
\end{aligned}
$$

These are the outputs the domestic firm produces under zero quota in bad state and good state, respectively. By substitution, the corresponding social welfare under zero quota is therefore given by

${ }^{8}$ Eldor and Levin (1990) and Chen and Hwang (2006) also derive similar outcome. 


$$
\begin{aligned}
E\left(S W^{Z Q}\right) & =\frac{1}{2}\left(P S_{L}^{Z Q}+C S_{L}^{Z Q}\right)+\frac{1}{2}\left(P S_{H}^{Z Q}+C S_{H}^{Z Q}\right) \\
& =\frac{1}{2}\left(\pi_{1 L}^{Z Q}+\frac{b}{2}\left(q_{1 L}^{Z Q}\right)^{2}\right)+\frac{1}{2}\left(\pi_{1 H}^{Z Q}+\frac{b}{2}\left(q_{1 H}^{Z Q}\right)^{2}\right) \\
& =\frac{3}{8 b}\left((a-c)^{2}+\sigma^{2}\right)
\end{aligned}
$$

where

$$
\begin{aligned}
\pi_{1 L}^{Z Q} & =\frac{1}{4 b}(a-c-V)^{2} \\
\pi_{1 H}^{Z Q} & =\frac{1}{4 b}(a-c+V)^{2}
\end{aligned}
$$

Needless to say, the domestic country is self sufficient under zero quota. ${ }^{9}$

\section{Free-Trade Quota}

Alternatively, the quota can be set at the expected free-trade level, i.e., the level of output the foreign firm wishes to produce for the domestic market when there is no government intervention of any kind. Obviously, the free-trade level quota, if imposed, is always binding since it is the level the foreign firm wants to export. Given that the foreign import is fixed by quota (which is state-independent), it is likely that the fully informed domestic firm may find it unprofitable to participate in production after the market condition becomes known. This occurs if the bad state of nature $-V$ is sufficiently negative. Our analysis below also takes this special scenario into consideration in addition to the usual case where two firms remain active in the market. As usual, we use superscript FT to indicate the variables under expected free-trade quota regime.

Our task here is to determine the free-trade level quota when it is set. Starting from stage two, the objective functions for the domestic firm in good and bad states are

$$
\begin{aligned}
& \pi_{1 L}^{F T}=\left(a-b\left(q_{1 L}^{F T}+q_{2}^{F T}\right)-V\right) q_{1 L}^{F T}-c q_{1 L}^{F T}, \\
& \pi_{1 H}^{F T}=\left(a-b\left(q_{1 H}^{F T}+q_{2}^{F T}\right)+V\right) q_{1 H}^{F T}-c q_{1 H}^{F T} .
\end{aligned}
$$

\footnotetext{
${ }^{9}$ Appendix B discusses the quota regime (zero quota and free-trade level quota) when the assumption of $V<\frac{8}{9}(a-c)$ is relaxed.
} 
Similarly, the problem for the foreign firm given common prior is

$$
\max _{q_{2}^{F T}} E\left(\pi_{2}^{F T}\right)=\frac{1}{2} \sum_{\varepsilon \in \Omega}\left(a-b\left(q_{1}^{F T}+q_{2}^{F T}\right)+\varepsilon\right)-c q_{2}^{F T},
$$

where $q_{1}^{F T} \in\left\{q_{1 L}^{F T}, q_{1 H}^{F T}\right\}$.

The best response functions for the above maximization problems are

$$
\begin{aligned}
B R_{1 L}\left(q_{2}^{F T}\right) & =q_{1 L}^{F T} \in \arg \max \pi_{1 L}^{F T}, \\
B R_{1 H}\left(q_{2}^{F T}\right) & =q_{1 H}^{F T} \in \arg \max \pi_{1 H}^{F T}, \\
B R_{2}\left(q_{1 L}^{F T}, q_{1 H}^{F T}\right) & =q_{2}^{F T} \in \arg \max E\left(\pi_{2}^{F T}\right) .
\end{aligned}
$$

Given these best response functions, the Bayesian Nash equilibrium output in absence of any government intervention are:

$$
\begin{aligned}
q_{1 L}^{F T} & =\frac{1}{3 b}(a-c)-\frac{1}{2 b} V, \\
q_{1 H}^{F T} & =\frac{1}{3 b}(a-c)+\frac{1}{2 b} V, \\
q_{2}^{F T} & =\frac{1}{3 b}(a-c) .
\end{aligned}
$$

The corresponding profits for the domestic firm in good and bad states are

$$
\begin{aligned}
& \pi_{1 L}^{F T}=\frac{1}{36 b}(2(a-c)-3 V)^{2}, \\
& \pi_{1 H}^{F T}=\frac{1}{36 b}(2(a-c)+3 V)^{2},
\end{aligned}
$$

respectively. Clearly, the domestic firm is active in low demand if and only if $V<\frac{2}{3}(a-c)$ or $\sigma^{2}<\frac{4}{9}(a-c)^{2}$ and becomes inactive otherwise. Two cases are considered:

1. $V<\frac{2}{3}(a-c)$

In this case, both firms remain active. One can obtain the domestic country's social welfare as follows: 


$$
\begin{aligned}
E\left(S W_{A}^{F T}\right) & =\frac{1}{2}\left(P S_{L}^{F T}+C S_{L}^{F T}\right)+\frac{1}{2}\left(P S_{H}^{F T}+C S_{H}^{F T}\right) \\
& =\frac{1}{2}\left(\pi_{1 L}^{F T}+\frac{b}{2}\left(q_{1 L}^{F T}+q_{2}^{F T}\right)^{2}\right)+\frac{1}{2}\left(\pi_{1 H}^{F T}+\frac{b}{2}\left(q_{1 H}^{F T}+q_{2}^{F T}\right)^{2}\right) \\
& =\frac{1}{3 b}(a-c)^{2}+\frac{3}{8 b} \sigma^{2}
\end{aligned}
$$

where the subscript $A$ indicates the case which the domestic firm is active even in low market demand.

2. $V \geq \frac{2}{3}(a-c)$

In this case, the domestic firm is not active when the bad state occurs. That is, the domestic firm sets $q_{1 L}^{F T}=0$. The best response functions for firms' problems can be rewritten as

$$
\begin{aligned}
B R_{1 H, N A}\left(q_{2, N A}^{F T}\right) & =q_{1 H, N A}^{F T} \in \arg \max \pi_{1 H}^{F T}, \\
B R_{2, N A}\left(q_{1 L}^{F T}=0, q_{1 H, N A}^{F T}\right) & =q_{2, N A}^{F T} \in \arg \max E\left(\pi_{2}^{F T}\right),
\end{aligned}
$$

where subscript $N A$ denotes the case when the domestic firm is not active when $-V$ realizes as true state. This yields

$$
\begin{aligned}
q_{1 H, N A}^{F T} & =\frac{2}{7 b}(a-c)+\frac{4}{7 b} V \\
q_{2, N A}^{F T} & =\frac{3}{7 b}(a-c)-\frac{1}{7 b} V
\end{aligned}
$$

Accordingly, the expected social welfare for the domestic country is given by

$$
\begin{aligned}
E\left(S W_{N A}^{F T}\right) & =\frac{1}{2}\left(C S_{L, N A}^{F T}\right)+\frac{1}{2}\left(P S_{H, N A}^{F T}+C S_{H, N A}^{F T}\right) \\
& =\frac{1}{2}\left(\frac{b}{2}\left(q_{2, N A}^{F T}\right)^{2}\right)+\frac{1}{2}\left(\pi_{1 H, N A}^{F T}+\frac{b}{2}\left(q_{1 H, N A}^{F T}+q_{2, N A}^{F T}\right)^{2}\right) \\
& =\frac{3}{14 b}(a-c)^{2}+\frac{2}{7 b}(a-c) \sigma+\frac{3}{14 b} \sigma^{2},
\end{aligned}
$$

where

$$
\pi_{1 H, N A}^{F T}=\frac{4}{49 b}((a-c)+2 V)^{2}
$$




\section{Zero Quota vs. Free-Trade Quota}

Given Cases 1 and 2 above, a straightforward comparison yields the following proposition.

Proposition 3. Under quota with incomplete information against the foreign firm, zero quota is always preferred by the domestic country.

Proof. We prove the proposition in two parts, depending on whether the domestic firm is active in low demand or not. First, we compare the expected social welfare level of the domestic country between zero quota and free-trade level quota if the domestic firm remains active in low demand. Denote

$$
\Delta_{1}=E\left(S W^{Z Q}\right)-E\left(S W_{A}^{F T}\right)=\frac{1}{24 b}(a-c)^{2}>0
$$

implying that zero quota dominates free-trade quota.

Next, compare the expected social welfare for the domestic country between zero quota policy and the free-trade quota policy if the domestic firm is not active in low demand. Calculate

$$
\begin{aligned}
\Delta_{2} & =E\left(S W^{Z Q}\right)-E\left(S W_{N A}^{F T}\right) \\
& =\frac{9}{56 b}(a-c)^{2}-\frac{2}{7 b}(a-c) \sigma+\frac{9}{56 b} \sigma^{2} .
\end{aligned}
$$

$\Delta_{2}$ appears to be strictly convex since $\frac{\partial \Delta_{2}}{\partial \sigma}=-\frac{2}{7 b}(a-c)+\frac{9}{28 b} \sigma \gtreqless 0$ and $\frac{\partial^{2} \Delta_{2}}{\partial \sigma^{2}}=\frac{9}{28 b}>0$. The minimum of $\Delta_{2}$ occurs at $\sigma_{\min }=\frac{8}{9}(a-c)$. At $\sigma=\sigma_{\min }, \Delta_{2}\left(\sigma_{\min }\right)=\frac{17}{504 b}(a-c)^{2}>0$. One can therefore conclude that $\Delta_{2}>0$ for all $\sigma^{2}$. In short, both $\Delta_{1}>0$ and $\Delta_{2}>0$, thus making zero quota a superior choice. The proposition is proven.

This proposition shows that if the domestic government uses a quota as a policy instrument, it will limit the volume of foreign import to zero, thereby making its own firm a monopolist. This result seems counter intuitive and can be understood by referring to Table 1 and Table 2. These two tables decompose the expected social welfare of the domestic country into two separate components (consumer's surplus and producer's surplus) under autarky (i.e., zero quota) and a quota at the freetrade level with active and inactive domestic firm in low market demand, respectively.

As seen in Table 1, a change from a quota at the free-trade level to autarky increases profits for the domestic firm (or producer's surplus) at the expense of consumers. This is because autarky makes the domestic firm a monopolist, allowing it to earn the monopoly rent. As a result, consumers suffer due 
Table 1: The Decomposition of $S W^{Z Q}$ and $S W_{A}^{F T}: V<\frac{2}{3}(a-c)$

\begin{tabular}{lll}
\hline Zero Quota & Free-Trade Quota & $\Delta_{1}$ \\
\hline
\end{tabular}

$$
\begin{array}{cccc}
\text { Producer's Surplus } & \frac{1}{4 b}\left((a-c)^{2}+\sigma^{2}\right) & \frac{1}{9 b}(a-c)^{2}+\frac{1}{4 b} \sigma^{2} & \frac{5}{36 b}(a-c)^{2} \\
\text { Consumer's Surplus } & \frac{1}{8 b}\left((a-c)^{2}+\sigma^{2}\right) & \frac{2}{9 b}(a-c)^{2}+\frac{1}{8 b} \sigma^{2} & -\frac{7}{72 b}(a-c)^{2} \\
\text { Social Welfare } & \frac{3}{8 b}\left((a-c)^{2}+\sigma^{2}\right) & \frac{1}{3 b}(a-c)^{2}+\frac{3}{8 b} \sigma^{2} & \frac{1}{24 b}(a-c)^{2}
\end{array}
$$

Table 2: The Decomposition of $S W^{Z Q}$ and $S W_{N A}^{F T}: V \geq \frac{2}{3}(a-c)$

\begin{tabular}{lll}
\hline Zero Quota & Free-Trade Quota & $\Delta_{2}$ \\
\hline
\end{tabular}

$$
\begin{array}{cccc}
\text { Producer's Surplus } & \frac{1}{4 b}\left((a-c)^{2}+\sigma^{2}\right) & \frac{2}{49 b}(a-c+2 \sigma)^{2} & \frac{41}{196 b}(a-c)^{2}+\frac{17}{196 b} \sigma^{2} \\
& & -\frac{8}{49 b}(a-c) \sigma \\
\text { Consumer's Surplus } & \frac{1}{8 b}\left((a-c)^{2}+\sigma^{2}\right) & \frac{17}{98 b}(a-c)^{2}+\frac{5}{98 b} \sigma^{2} & -\frac{19}{392 b}(a-c)^{2}+\frac{29}{392 b} \sigma^{2} \\
& & +\frac{6}{49 b}(a-c) \sigma & -\frac{6}{49 b}(a-c) \sigma \\
\text { Social Welfare } & \frac{3}{8 b}\left((a-c)^{2}+\sigma^{2}\right) & \frac{3}{14 b}(a-c)^{2}+\frac{3}{14 b} \sigma^{2} & \frac{9}{56 b}(a-c)^{2}+\frac{9}{56 b} \sigma^{2} \\
& & +\frac{2}{7 b}(a-c) \sigma & -\frac{2}{7 b}(a-c) \sigma
\end{array}
$$

to an increase in price, which is captured by the reduction in consumer's surplus. Nevertheless, the increase in producer's surplus more than offsets the decrease in consumer's surplus, resulting in a net increase in social welfare. The same pattern also holds for the case where the domestic firm becomes inactive when the realized demand is too low (see Table 2). In other words, prohibitive quota turns out to be the social-welfare-maximizing policy. In our model with asymmetric information, autarky is more desirable than quota at the free-trade level, since option value accrues exclusively to the domestic firm in the zero quota case. This result holds for all $\sigma^{2}$. It is confirmed that in the present case, the loss in consumer's surplus is more than offset by the gain in producer's surplus. This is seen in the last column of Table 2 where the welfare of the domestic country is shown to be positively correlated with $\sigma^{2}$.

Note that the second term associated with variance in equation (15) is the option value accruing 
to the domestic country, since the domestic firm, being fully informed, is able to make the output decision after the resolution of uncertainty. It is straightforward to show that $\frac{\partial E\left(S W^{Z Q}\right)}{\partial \sigma^{2}}>0$. Hence, an increase in market volatility increases the expected social welfare for the domestic country. This is summarized in the following proposition.

Proposition 4. Under the quota regime, the expected social welfare of the domestic country increases with market volatility.

\section{Choice of Policy Regimes}

In this section, we examine stage one problem regarding the choice of regime by the domestic government. As discussed in the previous section, autrky (or zero quota) is preferred to a quota at the free-trade level, regardless of the degree of uncertainty. Therefore, we need only compare tariff regime with the autarky.

Subtracting equation (15) from equation (9) yields

$$
\begin{aligned}
\Delta_{3} & =E\left(S W^{T}\right)-E\left(S W^{Z Q}\right) \\
& =\left(\frac{7}{18 b}(a-c)^{2}+\frac{3}{8 b} \sigma^{2}\right)-\left(\frac{3}{8 b}\left((a-c)^{2}+\sigma^{2}\right)\right) \\
& =\frac{1}{72 b}(a-c)^{2} .
\end{aligned}
$$

Note that $\Delta_{3}$ does not contain any option value term. The option value terms in equation (15) and equation (9) cancels out since tariff and zero quota regimes provide the domestic country with the same portion of the option value. Therefore, we can establish the following proposition. ${ }^{10}$

Proposition 5. In the market with incomplete information under demand uncertainty, the social welfare is unambiguously higher under a tariff than under a quota.

This result is in sharp contrast to Chen and Hwang (2006) in that the optimal policy is independent of the level of uncertainty. In their model, optimum policy is autarky (i.e., zero quota), quota at the free-trade level and tariff for high, intermediate and low levels of uncertainty respectively. The underlying reason behind their result is that a quota allows the domestic country to limit foreign firm's access to option values, particularly when the degree of uncertainty is high. This is because both foreign and domestic firms are fully informed and a tariff regime results in equal access to option

\footnotetext{
${ }^{10}$ Appendix $\mathrm{C}$ presents the detailed welfare ranking when the assumption of $V<\frac{8}{9}(a-c)$ is relaxed.
} 
values. However, in the present model with incomplete information, the foreign firm is uninformed about the true state of nature, and thus has no choice but to produce a state-independent output, which excludes it from capturing option value, associated with the ability to make decisions after the resolution of uncertainty. Therefore, the lack of information on the part of the foreign firm itself forces the option value to be redistributed in favor of the domestic firm. In this sense, keeping option values for the domestic firm through quotas can be similarly achieved when the domestic firm has information advantage over the foreign firm. This consequently marginalizes the need for a quota. But if a quota is used, it would be set at zero (see Proposition 3).

When it comes to the choice between autarky and a tariff, it is useful to focus on the relative magnitudes of consumer's surplus, producer's surplus and tax revenues as the policy regime changes from autarky to a tariff. From Table 3, it is clear that there is a significant loss in producer's surplus when the market structure changes from a monopoly to a duopoly as the country moves away from zero quota. At the same time, such a move clearly benefits consumers because of a lower output price due to competition. This is seen in $\Delta_{3}$, the last column of Table 3 . One can easily verify that the loss in producer's surplus is greater than an increases in consumer's surplus. Nevertheless, as we take into account tariff revenues $\frac{1}{27 b}(a-c)^{2}$ (see Row 3 of Table 3), the country ends up having higher social welfare.

The conventional result that views tariffs better than quotas is based on the argument that tariffs generate revenues for the country, but quotas do not. This holds in the absence of uncertainty. In the present model with a stochastic demand, our result is consistent with this strand of the literature. While the superiority of tariffs over quotas is explained by tariff revenues in the conventional literature, in our case it is driven by the role of information and its effect on the choice of policy regimes.

Table 3: Comparison and Decomposition of $S W^{T}$ and $S W^{Z Q}$

\begin{tabular}{lll}
\hline Tariff & Zero Quota & $\Delta_{3}$ \\
\hline
\end{tabular}

$\begin{array}{cccc}\text { Producer's Surplus } & \frac{16}{81 b}(a-c)^{2}+\frac{1}{4 b} \sigma^{2} & \frac{1}{4 b}\left((a-c)^{2}+\sigma^{2}\right) & -\frac{17}{324 b}(a-c)^{2} \\ \text { Consumer's Surplus } & \frac{25}{162 b}(a-c)^{2}+\frac{1}{8 b} \sigma^{2} & \frac{1}{8 b}\left((a-c)^{2}+\sigma^{2}\right) & \frac{19}{648 b}(a-c)^{2} \\ \text { Tax Revenue } & \frac{1}{27 b}(a-c)^{2} & 0 & \frac{1}{27 b}(a-c)^{2} \\ \text { Social Welfare } & \frac{7}{18 b}(a-c)^{2}+\frac{3}{8 b} \sigma^{2} & \frac{3}{8 b}\left((a-c)^{2}+\sigma^{2}\right) & \frac{1}{72 b}(a-c)^{2}\end{array}$




\section{Conclusion}

With regard to welfare equivalence of tariffs and quotas, it is well-known in the literature that tariffs are superior to quotas in models with no uncertainty. When demand is uncertain, the result becomes ambiguous. Specifically, the optimal policy can be autarky, a quota at the free-trade level, or even a tariff depending on whether the degree of uncertainty is high, medium, or low. The present paper considers a duopoly model with two firms (domestic and foreign) competing against each other in the domestic market and the output game involves information asymmetry. The asymmetric information adds a new dimension to the issue of welfare equivalence between tariffs and quotas. Our analysis of tariffs and quotas under incomplete information has generated the following novel results:

1. Under tariffs with incomplete information, the well-informed domestic firm produces less (more) relative to the full information case when the realized demand is low (high), whereas the illinformed foreign firm tends to produce a moderate level of output.

2. Higher degree of uncertainty implies higher expected social welfare for the domestic country due to option value effects, regardless of whether it is a tariff or a quota.

3. With incomplete information, a tariff is superior to a quota for all $\sigma^{2}$.

Our analysis is based on a set of simplified assumptions: two firms (domestic and foreign) with identical marginal cost, the linear demand with additive uncertainty, and a binary common prior over the uncertainty space that each state occurs with equal probability. With these admittedly restrictive assumptions, we are able to derive some interesting results that are new to the literature in our view. Nevertheless, our results can readily be extended to take into account more general cases such as the cost function being non-linear, an oligopoly with more than two firms, and different priors placed over uncertainty space in a dynamic setting. Our conjecture is that tariffs may still be superior as long as incomplete information persists at the industrial level, but we leave it for future research. 


\section{Appendices}

\section{A Import Tariffs}

Here, we consider the case in which the domestic firm finds it unprofitable to remain in the market when the realized demand is too low, i.e., $V \geq \frac{8}{9}(a-c)$. Our task is to find the optimal tariff rate, Bayesian Nash equilibrium level of output and expected social welfare for the domestic country when the domestic firm shuts down in a depressed market. We use subscript $N A$ to denote variables in this case.

Suppose now that the domestic firm set $q_{1 L}^{T}=0$ if it observes the domestic market demand is low, the new best response functions for the domestic firm and the foreign firm are

$$
\begin{aligned}
B R_{1 H, N A}\left(q_{2, N A}^{T}\right) & =q_{1 H, N A}^{T} \in \arg \max \pi_{1 H}^{T}, \\
B R_{2, N A}\left(q_{1 L}^{T}=0, q_{1 H, N A}^{T}\right) & =q_{2, N A}^{T} \in \arg \max E\left(\pi_{2}^{T}\right) .
\end{aligned}
$$

Given these new best response functions, we can solve for the new Bayesian Nash equilibrium points for any given tariff $t_{0}$ as

$$
\begin{aligned}
q_{1 H, N A}^{T} & =\frac{2}{7 b}\left(a-c+t_{0}\right)+\frac{4}{7 b} V \\
q_{2, N A}^{T} & =\frac{3}{7 b}(a-c)-\frac{4}{7 b} t_{0}-\frac{1}{7 b} V
\end{aligned}
$$

Folding back to stage one, the domestic government chooses tariff $t_{0}$ to maximizes the expected social welfare, given that the domestic government anticipates the strategic behavior of both firms in the second stage. Note that there is a change in the expected social welfare function for the domestic government in low market demand since the domestic firm now provides zero output in low market demand. Formally, the objective function for the domestic government is

$$
\begin{aligned}
\max _{t_{0}} E\left(S W_{N A}^{T}\right) & =\frac{1}{2}\left(C S_{L, N A}^{T}\right)+\frac{1}{2}\left(P S_{H, N A}^{T}+C S_{H, N A}^{T}\right)+T R_{N A} \\
& =\frac{1}{2}\left(\frac{b}{2}\left(q_{2, N A}^{T}\right)^{2}\right)+\frac{1}{2}\left(\pi_{1 H, N A}^{T}+\frac{b}{2}\left(q_{1 H, N A}^{T}+q_{2, N A}^{T}\right)^{2}\right)+t_{0} q_{2, N A}^{T},
\end{aligned}
$$

where

$$
\pi_{1 H, N A}^{T}=\frac{4}{49 b}\left(a-c+t_{0}+2 V\right)^{2} .
$$


Solving the optimization problem for the domestic government yields

$$
t_{0}^{*}=\frac{1}{3}(a-c)
$$

Note that $t_{0}^{*}=t^{*}$. This implies the choice of optimal tariff rate is not sensitive to whether the domestic firm is active or not in the bad state. Substituting $t_{0}$ into the Bayesian Nash equilibrium levels of output for the two firms, one obtains

$$
\begin{aligned}
q_{1 H, N A}^{T} & =\frac{8}{21 b}(a-c)+\frac{4}{7 b} V \\
q_{2, N A}^{T} & =\frac{5}{21 b}(a-c)-\frac{1}{7 b} V .
\end{aligned}
$$

Substituting these equilibrium values into first-order condition of equation (1) yields $V_{0}=\frac{8}{9}(a-c)$ - the critical point of $V$ so that the domestic firm stops producing in low market demand. Hence we can conclude that for any value of $V \in\left[\frac{8}{9}(a-c), \infty\right)$, the domestic firm will not be active in the low market demand.

Given these equilibrium values, we can now calculate the expected social welfare for the domestic country if the domestic firm is not active in low market demand under tariff regime as

$$
E\left(S W_{N A}^{T}\right)=\frac{11}{42 b}(a-c)^{2}+\frac{2}{7 b}(a-c) \sigma+\frac{3}{14 b} \sigma^{2}
$$

\section{B Import Quotas}

There are three cases that need to be considered under quota policy depending on whether the domestic firm is active or not when the market realizes low demand:

1. the domestic firm is active in low market demand under both zero quota policy and free-trade quota policy;

2. the domestic firm is active in low market demand under zero quota policy but inactive in low market demand under free-trade quota policy;

3. the domestic firm is not active in low market demand under either zero quota policy or free-trade quota policy.

Note that for the domestic firm to be active in low demand under zero quota policy we need $V<(a-c)$, 
and the domestic firm is active in low demand under free-trade quota if $V<\frac{2}{3}(a-c)$. Therefore, it is not possible that the domestic firm is active in low demand under free-trade quota but inactive in low demand under zero quota policy.

In section 3.2, we have conducted the analysis for the Case 1 (see equation (26)) and Case 2 (see equation (27)). We now conduct the equilibrium analysis for Case 3. Note that from equation (13), we can see that the domestic firm will not produce in low market demand under aurtaky if $V \geq(a-c)$. If this is the case, the expected social welfare for the domestic country (denoted as subscript $N A$ as usual) is

$$
\begin{aligned}
E\left(S W_{N A}^{Z Q}\right) & =\frac{1}{2}\left(P S_{H}^{Z Q}+C S_{H}^{Z Q}\right) \\
& =\frac{1}{2}\left(\pi_{1 H}^{Z Q}+\frac{b}{2}\left(q_{1 H}^{Z Q}\right)^{2}\right) \\
& =\frac{3}{16 b}(a-c+V)^{2}
\end{aligned}
$$

We are now ready to compare the expected social welfare under zero quota and free-trade quota if the domestic firm is not active when low market demand realizes under either policies. Subtracting equation (25) from equation (34) and denoting difference as $\Delta_{4}$, we have

$$
\begin{aligned}
\Delta_{4} & =E\left(S W_{N A}^{Z Q}\right)-E\left(S W_{N A}^{F T}\right) \\
& =\left(\frac{3}{16 b}(a-c+V)^{2}\right)-\left(\frac{3}{14 b}(a-c)^{2}+\frac{2}{7 b}(a-c) V+\frac{3}{14 b} V^{2}\right) \\
& =-\frac{1}{112 b}(3(a-c)-V)(a-c-3 V) .
\end{aligned}
$$

$\Delta_{4}$ is strictly concave since $\frac{\partial^{2} \Delta_{4}}{\partial V^{2}}=-\frac{3}{56 b}<0$. The maximum of $\Delta_{4}$ occurs at $V_{\max }=\frac{5}{3}(a-c)$. At $V=V_{\max }, \Delta_{4}\left(V_{\max }\right)=\frac{1}{21 b}(a-c)^{2}>0$. Moreover, $\Delta_{4}=0$ happens at $V=\frac{1}{3}(a-c)$ and $V=3(a-c)$. Given that $V \geq(a-c)$ in our Case 3, we then can conclude following results regarding to optimal quota policy:

- When $(a-c) \leq V<3(a-c), \Delta_{4}>0$, zero quota is preferred to free-trade quota;

- When $V=3(a-c), \Delta_{4}=0$, the domestic government is indifference between zero quota and free-trade quota;

- When $V>3(a-c), \Delta_{4}<0$, free-trade quota is preferred to zero quota.

Note that if we have a sufficient large $V(>3(a-c))$, free-trade quota seems to be optimal for the 
domestic country. This result is slight different from what we have analyzed in section 3.2. However, this result will not affect welfare ranking when choosing between tariffs and quotas as show in Appendix C.

\section{Welfare Comparison}

When we relax our assumption that random variable $V<\frac{8}{9}(a-c)$ in our main text, we shall consider four different possible cases regarding to whether the domestic firm will active or not in low market demand under different policy instruments similar to Appendix B for analysis of quotas. Hence we have

1. The domestic firm is active in low market demand under both tariff and quota;

2. The domestic firm is active in low market demand under tariff, but inactive in low market demand under quota;

3. The domestic firm is not active in low market demand under tariff, but active in low market demand under quota;

4. The domestic firm is not active in low market demand under either tariff or quota.

We have covered Case 1 and Case 2 in section 4 as we assumed $V<\frac{8}{9}(a-c)$ throughout our equilibrium analysis. For easy comparisons, we first restate our results from the main text ( Case 1 and Case 2, respectively) and then conduct our welfare analysis for Cases 3 and 4 where the domestic firm becomes inactive. By analyzing all four cases, we can show that a tariff is optimal for all $V \in \mathbb{R}$.

\section{Case 1}

In this case, the random variable $V$ satisfies $V<\frac{2}{3}(a-c)$. Given that the optimal quota policy is zero quota, $\Delta_{3}$ (see equation (28)) implies a tariff is preferred to a quota at zero leval.

\section{Case 2}

The random variable $V$ falls in the range $\left[\frac{2}{3}(a-c), \frac{8}{9}(a-c)\right)$ in this case. Similar to Case 1, given that the optimal quota policy is autarky, $\Delta_{3}$ (see equation (28)) implies that a tariff is preferred. 


\section{Case 3}

In this case, the stochastic term $V$ shall falls in the range $\left[\frac{8}{9}(a-c),(a-c)\right)$. Note that the optimal quota policy is also zero quota if quota is considered. Define

$$
\begin{aligned}
\Delta_{5} & =E\left(S W_{N A}^{T}\right)-E\left(S W^{Z Q}\right) \\
& =\left(\frac{11}{42 b}(a-c)^{2}+\frac{2}{7 b}(a-c) \sigma+\frac{3}{14 b} \sigma^{2}\right)-\left(\frac{3}{8 b}\left((a-c)^{2}+\sigma^{2}\right)\right) \\
& =\frac{19}{168 b}(a-c)^{2}+\frac{2}{7 b}(a-c) \sigma+\frac{9}{56 b} \sigma^{2} .
\end{aligned}
$$

$\Delta_{5}$ is strictly concave since $\frac{\partial \Delta_{5}}{\partial \sigma}=\frac{2}{7 b}(a-c)-\frac{9}{28 b} \sigma \gtreqless 0$ and $\frac{\partial^{2} \Delta_{5}}{\partial \sigma^{2}}=-\frac{9}{28 b}<0$. The maximum of $\Delta_{5}$ occurs at $\sigma_{\max }=\frac{8}{9}(a-c)$. At $\sigma=\sigma_{\max }, \Delta_{5}\left(\sigma_{\max }\right)=\frac{1}{72 b}(a-c)^{2}>0$. Moreover, $\Delta_{5}(\sigma=(a-c))=$ $\frac{1}{84 b}(a-c)^{2}>0$. We can conclude that $\Delta_{5}>0$ given $V \in\left[\frac{8}{9}(a-c),(a-c)\right)$. Hence, a tariff is preferred to a quota under Case 3.

\section{Case 4}

The last case is $V \geq(a-c)$. According to Appendix B, the optimal quota policy is either zero quota or a quota at the free-trade level depending on the cut-off point $V=3(a-c)$.

For $V \leq 3(a-c)$, we subtract equation (34) from equation (33) and define

$$
\begin{aligned}
\Delta_{6} & =E\left(S W_{N A}^{T}\right)-E\left(S W_{N A}^{Z Q}\right) \\
& =\left(\frac{11}{42 b}(a-c)^{2}+\frac{2}{7 b}(a-c) V+\frac{3}{14 b} V^{2}\right)-\left(\frac{3}{16 b}(a-c+V)^{2}\right) \\
& =\frac{1}{336 b}(5(a-c)-3 V)^{2},
\end{aligned}
$$

which is always positive.

On the other hand, for $V>3(a-c)$, we shall instead subtract equation (25) from equation (33) and define

$$
\begin{aligned}
\Delta_{7} & =E\left(S W_{N A}^{T}\right)-E\left(S W_{N A}^{F T}\right) \\
& =\left(\frac{11}{42 b}(a-c)^{2}+\frac{2}{7 b}(a-c) \sigma+\frac{3}{14 b} \sigma^{2}\right) \\
& -\left(\frac{3}{14 b}(a-c)^{2}+\frac{2}{7 b}(a-c) \sigma+\frac{3}{14 b} \sigma^{2}\right) \\
& =\frac{1}{21 b}(a-c)^{2},
\end{aligned}
$$


which is positive.

Given that $\Delta_{6}>0$ and $\Delta_{7}>0$, the optimal policy is again a tariff under Case 4 .

Cases 1-4 allow us to conclude that a tariff is always superior to a quota for all $V \in \mathbb{R}$. 


\section{References}

Bhagwati, J. (1965) On the equivalence of tariffs and quotas, in Trade, Growth and the Balance of Payments: Essays in Honor of Gottfried Haberler (Ed.) R. E. Baldwin, Rand McNally, Chicago.

Bhagwati, J. (1968) More on the equivalence of tariffs and quotas, The American Economic Review, $\mathbf{5 8}, 142-146$.

Chen, H. Y. and Hwang, H. (2006) Tariffs versus quotas under market price uncertainty, Review of World Economics, 142, 181-194.

Cooper, R. and Riezman, R. (1989) Uncertainty and the choice of trade policy in oligopolistic industries, The Review of Economic Studies, 56, 129-140.

Dasgupta, P. and Stiglitz, J. (1977) Tariffs vs. quotas as revenue raising devices under uncertainty, The American Economic Review, 67, 975-981.

Eldor, R. and Levin, D. (1990) Trade liberalization and domestic monopoly: a welfare analysis, International Economic Review, 31, 773-782.

Fishelson, G. and Flatters, F. (1975) The (non-)equivalence of optimal tariffs and quotas under uncertainty, Journal of International Economics, 5, 385-393.

Fung, K. C. (1989) Tariffs, quotas, and international oligopoly, Oxford Economic Papers, 41, 749-757.

Hwang, H. and Mai, C. C. (1988) On the equivalence of tariffs and quotas under duopoly: a conjectural variation approach, Journal of International Economics, 24, 373-380.

Itoh, M. and Ono, Y. (1984) Tariffs vs. quotas under duopoly of heterogeneous goods, Journal of International Economics, 17, 359-373.

Matschke, X. (2003) Tariff and quota equivalence in the presence of asymmetric information, Journal of International Economics, 61, 209-223.

Ning, H. (2020a) Choice of trade policy with incomplete information, manuscript, York University.

Ning, H. (2020b) Strategic trade policy in reciprocal dumping model with incomplete information, manuscript, York University. 
Shibata, H. (1968) A note on the equivalence of tariffs and quotas, The American Economic Review, 58, 137-142.

Weitzman, M. L. (1974) Prices vs. quantities, The Review of Economic Studies, 41, 477-491. 